\title{
El cocoliche en cuestión
}

\author{
Ángela Di Tullio ${ }^{\bullet}$ \\ Instituto de Filología «Dr. Amado Alonso»
}

\section{Resumen}

El cocoliche es una variedad surgida a partir del contacto entre el español y el italiano en determinadas condiciones históricas - en particular, las dos grandes oleadas de 18801914 y 1945-1955- y geográficas —la región del Litoral argentino. Si bien reducido por procesos de selección y simplificación, se nutrió de los diferentes dialectos italianos. El cambio de lengua de los inmigrantes tuvo envergadura social: el resultado del contacto entre lenguas y dialectos diferentes incidió en muchas de sus características más llamativas de la llamada "peculiaridad lingüística rioplatense».

\section{Palabras clave}

· Contacto $\cdot$ dialecto $\cdot$ pluriformismo $\cdot$ italianismo

\begin{abstract}
Cocoliche is a variety arising from the contact between Spanish and Italian in historical and geographic conditions -in particular, the two great waves of 1880-1914 and 19451955 and the region of the Argentine Coast, respectively. Although reduced by selection and simplification processes, it was nourished by the different Italian dialects. The change of the immigrant's language had social importance: the result of the contact among different languages and dialects affected many of the most striking characteristics of the so-called «River Plate linguistic peculiarity».

\section{Key words}

· Contact · dialect · pluriformism · italianism
\end{abstract}

\footnotetext{
- Profesora e investigadora en temas de gramática y de historia de la lengua, en particular referidos al español rioplatense; autora de/ Manual de gramática del español, de Políticas lingüísticas e inmigración: el caso argentino, entre otras obras escritas o editadas, además de numerosos capítulos de libros y artículos, y profesora de cursos de posgrado en Argentina y en el extranjero.
} 


\section{El cocoliche histórico}

Entre las diferentes variedades dialectales del español la de la región rioplatense se distingue en su registro coloquial por una serie de rasgos lingüísticos (fonéticos, prosódicos, léxicos y gramaticales) y paralingüísticos (la gesticulación) en los que autores como Meo Zilio (1965), Golluscio de Montoya (1990), Fontanella de Weinberg (1996), Cancellier (1996), Colantoni \& Gurnekian (2003), Di Tullio (2003), entre muchos otros, han reconocido la influencia del italiano como el precipitado de un proceso histórico en el que los italianos constituyeron el grupo inmigratorio más numeroso y visible de la experiencia del contacto. Este largo y complejo proceso supuso un esfuerzo cooperativo de acomodación y ajuste entre las variedades habladas por los inmigrantes y los criollos en las zonas populares. El resultado fue doble: una variedad híbrida —el cocoliche - y un argot urbano —el lunfardo. La densidad del bilingüismo, establecido entre las múltiples formas de la selva dialectal italiana y el habla rioplatense, se pone de manifiesto en la formación de una variedad híbrida, objeto de estigmatización, el cocoliche, y de un argot, el lunfardo, definido como "un vocabulario de ascendencia inmigratoria», que ha ido ganando aceptación social como modalidad coloquial de Buenos Aires (Conde, Teruggi).

El cocoliche es una variedad surgida a partir del contacto entre el espańol y el italiano en determinadas condiciones históricas y geográficas: el contexto inmigratorio rioplatense queda acotado por las dos grandes oleadas de 1880-1914 y 1945-1955, sobre todo en la zona del Litoral argentino. En este nuevo medio se recreó el mosaico dialectal italiano, aunque reducido por los procesos de selección y simplificación que se suelen operar en situaciones de transferencia de lenguas y culturas. Dadas estas condiciones, se trata de una variedad en vías de extinción —e incluso prácticamente desaparecida.

El cambio de lengua de los inmigrantes tuvo envergadura social: el resultado del contacto entre lenguas y dialectos diferentes incidió en muchas de sus características más llamativas de lo que el filólogo Américo Castro denominó en términos críticos «la peculiaridad lingüística rioplatense»:

La fonética y la entonación, a veces la sintaxis e infinidad de vocablos revelan la huella de[1 italiano y de] sus dialectos en la lengua de Buenos Aires. Un cierto aire de desgarro y cinismo plebeyos ha soplado a su favor, y ha sido a su vez favorecido por tales influjos. (Castro, 1941: 124)

En ese sentido resultan muy significativos los empleos del término en las memorias de Bioy Casares dedicadas a Borges (2006): a través de las casi 1500 páginas se emplea a menudo el adjetivo cocoliche como sustantivo o como adjetivo valorativo negativo. Así, por ejemplo, acerca de Roberto Giusti, codirector de la revista Nosotros, decía Borges: «Habla y escribe en cocoliche» (446) y cita burlonamente una de sus frases, en la que mezclaba el español peninsular con el italiano argentinizado: «Un mancebillo mezzo locatelli» (490). Esa mezcla es objeto de burla en relación con un crítico literario de apellido italiano: «Mantiene el acento cocoliche; fíjate 
en los adjetivos que usa: deleitoso» (1211), y a propósito de un verso poco feliz de Molinari: «QQué cocoliche!» (180). De la película Hombre de la esquina rosada Borges criticaba un rasgo que atribuía a los italianos: «Los personajes son demasiado expresivos para las escenas que ocurren». Y concluía observando con resignación: «Seguramente los argentinos hablamos y gesticulamos como cocoliches» (795).

\section{El cocoliche: ¿lengua, dialecto, jerga?}

El término cocoliche ha recibido diferentes definiciones como variedad lingüística en los diccionarios de argentinismos (de la época inmigratoria las dos primeras; más recientes las restantes):

- «Lenguaje híbrido que usan los extranjeros, particularmente los italianos ignorantes de nuestra lengua» (Tobías Garzón. Diccionario argentino, 1910); - «Castellano chapurreado y macarrónico que usan los extranjeros ignorantes y en especial los italianos» (Lisandro Segovia. Diccionario de argentinismos, neologismos y barbarismos, 1911);

- «Lengua torpe y ridícula del italiano inmigrado» (Gobello)

- «Variedad de castellano italianizado resultante de la gran inmigración itálica en el Río de la Plata» (Mario Teruggi. Diccionario de voces lunfardas rioplatenses, 1998);

- «Lenguaje característico del italiano al comenzar a aprender nuestra lengua: italiano acriollado...» (Félix Coluccio y Susana Coluccio. Diccionario folklórico argentino, 2006);

- "Jerga híbrida y grotesca que hablan ciertos inmigrantes italianos mezclando su habla con el espańol» (Oscar Conde. Diccionario etimológico del lunfardo, 2004)

- "Jerga mezclada de italiano y espańol, propia del período inmigratorio, difundida y recreada por el sainete a principios de este siglo» (Diccionario del habla de los argentinos).

La secuencia de estas definiciones pone de manifiesto la dificultad de caracterizar el concepto de cocoliche como una lengua, un dialecto o una jerga. Incluso el concepto de jerga que se emplea tiene más que ver con el de jerigonza ${ }^{1}$ (es decir, lenguaje difícil de entender) que con la definición general de «lenguaje especial y familiar que usan entre sí los individuos de ciertas profesiones y oficios», que a veces se aplica al lunfardo, y menos aún con el significado técnico, propio de los estudios especializados en las lenguas de contacto, que define al primer estadio, el más primitivo, de estas variedades (Appel y Muysken, 1996: 262).

Aunque de ninguna manera cabe deducir que se haga referencia a una lengua autónoma, tampoco se aclara si se trata de una variedad subordinada al español o al italiano. Por otra parte, los componentes denotativos se entrecruzan con los valorativos, como lo indican, además del nombre mismo, los adjetivos peyorativos que se incluyen en varias de las definiciones. 


\section{La polisemia del término cocoliche}

José Podestá, director de la compañía que organizó el sistema teatral argentino, cuenta en sus memorias (1930) cómo nació en 1890 el personaje que constituirá uno de los éxitos de su compañía, que se presentaba así: «-Ma quiame Franchisque Cocoliche, e songo cregollo gasta lo güese de la taba e la canilla de lo caracuse, amigue, afficate la parata...» (Podestá, 1930: 66). La manera defectuosa de hablar y la pretensión disparatada de parecer criollo son los dos rasgos característicos del personaje, que sirve de contrapunto cómico al gaucho Juan Moreira. El personaje concreto, que surge en esa circunstancia particular, pasa a ser una presencia obligatoria del teatro costumbrista argentino, y de allí se proyecta como máscara en el carnaval y como tipo por su manera de vestir o de actuar: "persona mal vestida o grotesca» (Teruggi).

El nombre del personaje se expande también como denominación de la lengua del inmigrante, primero en la recreación paródica del teatro y luego en la realidad que refleja: «lengua torpe y ridícula del italiano inmigrado» (José Gobello).

A Borges le debemos una nueva acepción, la del cocoliche como objeto académico de lingüistas: «No adolecemos de dialectos, aunque sí de institutos dialectológicos» (en clara alusión al Instituto de Filología, dirigido por Amado Alonso, que había creado el Boletín de Dialectología, al que acusaba, con punzante ironía, de inventar jergas y dialectos, inexistentes en Argentina: «Han improvisado el gauchesco, a base de Hernández, el cocoliche, a base de un payaso que trabajó con los Podestá; el vesre, a base de los alumnos de cuarto grado» (O.C., 654).

\section{Ubicación del cocoliche entre las variedades lingüísticas}

La abundancia de italianismos en las lenguas europeas pone de manifiesto el prestigio del que gozaron la cultura y el arte italiano, sobre todo en la época del Humanismo. Entre los italianismos internacionales se cuentan voces del léxico de la música (como aria, piano, allegro, vivace, mezzosoprano), las artes plásticas (como témpera, acuarela, olio, terracota), la literatura (soneto, novela) y de otros sectores como la vivienda, el deporte, el espectáculo, la gastronomía, la vestimenta, la guerra, a los que Italia contribuyó en sus aspectos espirituales y materiales. En el caso del español, el contacto fue más profundo y duradero durante los Siglos de Oro por las conquistas españolas en la región meridional (Sicilia, Cerdeña, Nápoles) y en Milán, como lo atestigua, además, el léxico de la guerra: escolta, centinela, carromato, batallón (Verdonk, 2005: 897-898). Aun así, fue más restringido que el que se produjo entre el italiano y el español en el Río de la Plata (Meo Zilio, 1960), ya que estuvo limitado tanto en cantidad como en su variedad: no se extendió a las áreas del vocabulario de la vida cotidiana, no incluyó préstamos fonéticos o gramaticales y, sobre todo, no supuso bilingüismo social. 
En cambio, el área rioplatense es la que cuenta con mayor número de italianismos no solo entre las variedades del español sino también en relación con otras lenguas del mundo. Muchos se incorporaron con los referentes y no pasaron por la mediación del lunfardo, como es el caso del léxico de la gastronomía, grisín, capuchino o pizza ${ }^{2}$, pero también a otros aspectos de la vida cotidiana como banquina, fratacho, cucha, aunque los que se registraron más tempranamente son los propios de la "mala vida», como bufoso, escrushar, chafo, esparar.

El cocoliche fue precisamente el resultado de una situación de contacto extendido a todas las esferas de la vida de relación entre dos grupos sociales que hablaban lenguas genéticamente emparentadas, muy similares en su estructura flexiva y en su sintaxis. De hecho, mantuvo un grado considerable de complejidad gramatical, a diferencia de lo que ocurre en los pidgins, surgidos del contacto entre lenguas muy diferentes desde el punto de vista genético y estructural, lo que incide en una notable reducción tanto de su léxico como de su gramática. Por otra parte, como estas variedades provienen del contacto en el ámbito comercial o en sociedades esclavistas, no cubre todas las esferas ni las funciones de una lengua natural; además, la vida del pidgin coincide con la duración del contacto.

Sin embargo, un pidgin puede convertirse en la lengua materna de una comunidad, con el consiguiente enriquecimiento interno y funcional; el resultado es una lengua criolla, que se transmite a las nuevas generaciones. Por el contrario, la expansión del cocoliche depende de diversas condiciones geográficas — tiene mayores posibilidades de supervivencia en el medio rural que en el urbano (Fontanella de Weinberg, Hipperdinger) —, culturales y personales. Por lo general, el hablante cocoliche está condenado a un intercambio asimétrico ya que, si bien sus hijos pueden llegar a entenderlo, no lo hablan, salvo como estrategia cooperativa, como se tematiza en obras teatrales de Florencio Sánchez o de Armando Discepolo.

\section{El cocoliche, variedad subordinada}

La cercanía genética y tipológica entre italiano y español contribuye a que sus límites se vuelvan difusos, lo que provoca interferencias y contaminaciones recíprocas. A diferencia del pidgin y de los criollos, el cocoliche no es una lengua autónoma, pero no hay acuerdo acerca de dónde ubicarlo: mientras que los Coluccio lo entienden como una variedad del italiano hablado fuera de Italia por emigrados italianos, Segovia y Teruggi lo consideran una variedad del español.

$\mathrm{Y}$ es que más que de una única variedad, el cocoliche es un continuum formado por diferentes estadios; en efecto, entre el desmoronamiento de la variedad italiana y la adquisición, total o parcial, de la rioplatense se suceden las interlenguas correspondientes a las sucesivas hipótesis de este continuum. Así, los Colluccio destacaban el segmento que va del polo italiano al «italiano acriollado», en tanto que Segovia y Teruggi al «castellano chapurreado y macarrónico» que se va acercando gradualmente al polo del español rioplatense.

En el proceso de pérdida de la L1 y de adquisición de L2 inciden factores cognitivos y sociales. El hablante cocoliche va perdiendo la capacidad de conmutar las dos lenguas (code switching) según su intención estilística, de manera que se va 
quedando con un único medio expresivo. Los psicolingüistas que han estudiado este proceso de desgaste y pérdida de la L1, que ha recibido la denominación de language attrition, lo definen así:

By «attrition», broadly defined by Freed (1982: 1) as «loss of any language or any portion of a language by an individual or a speech community», we mean a change in the L1 caused by a second language that has become the primary, that is, the most frequently used language. Language attrition has been studied predominantly as second language (L2)-induced first language (L1) attrition, that is, L1 attrition in (late) L2 environments due to migration to another country (expatriation)... The closer the languages and the more structures they share, the more interference is to be expected. (Köpke, 2007: 9-37)

En este párrafo la autora, Bárbara Köoke, describe el dramático proceso de la pérdida de la lengua materna en el contexto inmigratorio y destaca la incidencia de la cercanía estructural entre las lenguas en contacto como factor que favorece las interferencias. También reconoce factores sociales e individuales que pueden incidir en su duración y en la calidad del resultado, como los siguientes:

- la edad de arribo: la adquisición de L2 es más rápida y eficaz en los más jóvenes por la plasticidad del cerebro, que también incide en la mayor capacidad de inhibir la L1;

- el grado de alfabetización y de escolaridad incide positivamente en la adquisición de L2;

- el tiempo de permanencia en el país y las redes sociales —endogámicas o exogámicas - privilegiadas: en ámbitos rurales L1 es posible la formación de islas lingüísticas que preservan L1; en las ciudades no;

- las actitudes y motivaciones, como la voluntad de asimilarse al nuevo medio.

\section{Carácter inestable y cambiante del cocoliche}

En su efímera vida el cocoliche se mantiene en continuo cambio, con múltiples variantes, como es propio de las variedades no estandarizadas:

- Pluriformismo: en un mismo hablante alternan la supresión de la $-s$ final con su mantenimiento, a veces reforzado por - e paragógica: «Ma entonce no la había conucido [...] ¡Non siento mase come ante la volontá! Soy lo’stúpido... Ella se ríe, sa ríen los dos» (Carlos M. Pacheco, Los disfrazados).

- Variación estilística limitada: así, en La gringa de Florencio Sánchez, la alternancia entre vos y usted no atiende a las condiciones pragmáticas que regulan su empleo; Nicola se dirige a su mujer de dos maneras diferentes: Vos, cállese y Usted calláte, ambas erróneas por falta de concordancia entre pronombre y verbo.

- Fluctuación entre los dos polos: al haber perdido la capacidad de alternar las variedades, el hablante cocoliche combina en la misma frase expresiones de las dos lenguas, como se ve en 
el siguiente pasaje de Mustafá: casi todas las regiones italianas estuvieron presentes en el siguiente pasaje de Mustafá: «iPer qué a Bonasaria está saliendo esta razza forte? Perque éste ese no paíse hospitalario que te agarra toda la migraciones, te la encaja a lo conventillo, viene la mescolanza e te sáleno a la calle esto lindo mochacho pateadore, boxeadore, cachiporrero, e asaltante de la Madonna» (A. Discépolo y J. De Rosa).

\section{El cocoliche como objeto de estudio}

Las características enumeradas del cocoliche -inestabilidad, variación, pluriformismo, fijación estilística- lo tornan un objeto de estudio escurridizo, inaprensible, del que resulta imposible formular una gramática. Tampoco existen diccionarios de cocoliche, aunque sí de argentinismos y de lunfardismos. Como el cocoliche real es hoy una variedad prácticamente desaparecida, es difícil e incluso imposible estudiarlo con la metodología lingüística, basada en juicios de gramaticalidad, en trabajos estadísticos a partir de corpus, en grabaciones del habla espontánea. Tampoco suele ser accesible el material de archivo: cartas familiares y otros materiales escritos.

Por eso, como señalaba Borges en su mordaz referencia al Instituto de Filología, el "cocoliche académico» se basaría en la descripción de la lengua de los personajes del circo, o del género chico teatral. De hecho, los estudios de la lengua inmigratoria no se han basado por lo general en entrevistas, cuestionarios, encuestas, sino casi exclusivamente a través de obras literarias que lo representan. $\mathrm{Al}$ ir desapareciendo el cocoliche real con los últimos inmigrantes, la literatura —en sentido amplio- se ha convertido en la única vía de acceso, aunque lo fue incluso cuando existía una población que empleaba el cocoliche. Esta opción metodológica no está exenta de peligros, puesto que los autores a menudo pretenden, más que una representación fidedigna del cocoliche real, crear el efecto cocoliche, pero parece ineludible debido a las dificultades inherentes a su estudio.

En la actualidad ya no es posible reparar esta falta de material auténtico, puesto que los hablantes cocoliches aún vivos sufren por lo general un deterioro de su sistema producido por la edad y por una "crisi di rigetto, che porta l'emigrato a non saper più... comunicare ad un "livello soglia" minimamente accettabile» (Lo Cascio. 1987. 92). Aunque, desde el punto de vista metodológico, no sea legítimo tratar la versión literaria del cocoliche como un mero reflejo de la realidad lingüística, los textos en cocoliche han constituido un testimonio muy valioso para acercarse, con los debidos recaudos, al cocoliche real, como lo reconocen implícitamente las antologías del cocoliche que acompañan a algunos de los estudios (Meo Zilio, 1964; Rosell, 1970).

Por otra parte, en los escasos estudios de campo sobre el cocoliche, como el de Lavandera ( El componente variable» en Variación y significado) referido a la falta de alternancia modal en los hablantes cocoliches, los contextos que probarían esta «incapacidad» se reducen al discurso directo, que exime del empleo del subjuntivo regido por verbos intensionales. Aunque la lingüista corrige el discurso directo del hablante cocoliche con el correspondiente discurso indirecto, no parece ser este un 
rasgo atribuible al cocoliche sino, más bien, al registro coloquial y, sobre todo, a la lengua expresiva que permite representar la polifonía del lenguaje de manera vívida. La selección del discurso directo depende, entonces, del registro en que el hablante se expresa, y no de su condición bilingüe o monolingüe; por lo menos no se demuestra la hipótesis a través de un análisis comparativo con hablantes monolingües.

\section{Cocoliche e italianismos}

El término cocoliche designa, en principio, el resultado incompleto e insatisfactorio de la adquisición del español por parte del inmigrante italiano —es decir, un proceso individual—, pero se configura socialmente como medio de expresión de un grupo en un determinado período histórico. El término se caracteriza también por haber designado la variedad inmigratoria más visible y expandirse a otros significados, por cristalizarse como convención del género en la literatura popular y por convertirse en el blanco de los ataques del medio intelectual de la época. Su interés fundamental reside en ser la principal vía de acceso del italianismo, que el lunfardo elabora, expande con frecuentes derivaciones metafóricas, y fija, además de excederlo en el tiempo, en el espacio y en la amplitud social de los hablantes que lo emplean.

Si se hiciera abstracción de la situación histórica y de la dirección en el proceso de adquisición, podría pensarse el cocoliche como «la variedad defectuosa en la interacción bilingüe entre espańol e italiano», es decir, como la zona en que ambas lenguas difieren en la fonética, el léxico o la gramática o, más concretamente, el espacio no compartido en el que se concentran los errores, las interferencias, las contaminaciones propias de la adquisición de L2 tanto para aprendices de español como de italiano. Sin embargo, esta abstracción difiere de manera sustantiva del cocoliche histórico, no solo por los cambios registrados en el italiano y en la variedad rioplatense del español, sino también porque las circunstancias de la inmigración incidieron notablemente en la valoración de esa variedad.

\footnotetext{
Notas

${ }^{1}$ De jerigonza Garzón derivaba el término gringo, que en el diccionario académico se remontaba a griego.

${ }^{2}$ Aunque los dos últimos vocablos hoy son italianismos internacionales, vale la pena destacar que ya eran corrientes en Buenos Aires en la década del '30, como lo demuestra el hecho de que Arlt los usara en sus Aguafuertes porteñas.
} 


\section{Referencias bibliográficas}

Academia Argentina de Letras (2008). Diccionario del habla de los argentinos. Buenos Aires: Espasa

Appel, R. y Muysken, P. (1996). Bilingüismo y contacto de lenguas. Barcelona: Ariel lingüística.

Arlt, R. (1933). Aguafuertes. Obras II. Madrid: Losada.

Bioy Casares, A. (2005). Borges. Buenos Aires: Destino.

Borges, J.L. (1973). Obras completas. Buenos Aires: Emecé.

Cancellier, A. (1996). Lenguas en contacto. Italiano y español en el Río de la Plata. Padua: Unipress.

Castro, A. (1941). La peculiaridad lingüistica rioplatense. Madrid: Taurus. 2o ed. 1961 .

Colantoni, L. y Gurlekian, J. (2004). «Convergence and intonation: historical evidence from Buenos Aires Spanish» en Bilingualism Language and Cognition 7(2). 107-119.

Conde, O. (2011). Lunfardo. Un estudio sobre el habla popular de los argentinos. Buenos Aires: Taurus.

(2005). Diccionario etimológico del lunfardo. Buenos Aires: Taurus.

Coluccio, F. y Coluccio, S. (1999). Diccionario folklórico argentino. T1. Buenos Aires: Plus Ultra.

Discepolo, A. (1969). Obras escogidas. Prólogo de David Viñas. 3 vol. Buenos Aires: Jorge Álvarez.

Di Tullio, A. (2013). «Aspectos morfosintácticos del español argentino resultantes del contacto con el italiano» en Colantoni, L. y RodríGUEZ Louro, C. (2013). Perspectivas teóricas y experimentales sobre el español de la Argentina. Berlín: Verveurt, pp. 439-452.

_ (2012). «Italianismos en el español de la Argentina» en PATAT, A. y Villarini, A. (2012) Gli italianismi in Argentina. Roma: Quodlibet Studio, pp. 31-48.

Fontanella de Weinberg, M.B. (1996). «Contacto lingüístico: lenguas inmigratorias». Signo \& Seña. 6. 437-457.

(1994). "Una fugaza con fetas de panceta y provolone”. La incorporación léxica en el español bonaerense» en AAVV (1994) Estudios sobre el español de la Argentina. Bahía Blanca: Universidad Nacional del Sur, pp. 51-77.

Garzón, T. (1910). Diccionario argentino. Barcelona: Imprenta Elzeveriana de Borrás y Mestre.

Gobello, J. (1999). Nuevo diccionario lunfardo. Buenos Aires: Corregidor. Hipperdinger, Y. (2007). «La inmigración italiana en Bahía Blanca. Cuestiones lingüísticas» en Magnani, I. (ed). Il ricordo e l'immagine. Vechia e nuova identità italiana in Argentina. Santa Maria Capua Vetere: Spartaco, pp. 30-42.

Köpke, B. (2007). «Language attrition at the crossroads of brain mind and society» en Köpke, B. et al. (2007). Language Attrition. Pp. 9-37. [En línea] Consulta $09-12$ - 2018 en https://hal.archives-ouvertes.fr/ hal-00981119/document 
LaVANdera, B. (1984). «El componente variable en el uso verbal bilingüe» en Lavandera, B. (1984). Variación y significado. Buenos Aires: Hachette, pp. 57-74.

Lo Cascio, V. (1987). «L'emigrazione italiana: aspetti sociali e linguistici» en Lo Cascio, V. (ed.). Litaliano in America Latina. Firenze: Felice Le Monnier, pp. 89-118.

Meo ZıLıo, G. (1965). «Italianismos generales en el español rioplatense» BICC. XX. 68-119.

Podestá, J. (1930). Medio siglo de farándula. Estudio Preliminar de O. Pellettieri. Buenos Aires: Galerna. 2003.

Rosell, A. (1970). El cocoliche. Montevideo: Disa.

SÁnchez, F. (1904). La gringa. Buenos Aires: Huemul. 1970.

Selva, J. (1906). El castellano en América. Buenos Aires: Librería de García Santos.

Teruggi, M. (1998). Diccionario de voces lunfardas rioplatenses. Buenos Aires: Alianza.

Verdonk, R. (2005). «Cambios en el léxico del español durante la época de los Austrias» en Cano, R. (coord.). Historia de la lengua española. Barcelona: Ariel, pp. 895-916.

\section{Di Tullio, Ángela}

«El cocoliche en cuestión». El hilo de la fábula. Revista anual del Centro de Estudios Comparados (19), 127-136. 